\title{
Research on Cultic Dynamics From Perspective of Internet ${ }^{*}$
}

\author{
Peng Xue ${ }^{1}$, Baoxiang Fan ${ }^{1}$ \\ ${ }^{1}$ Center for the Study of Cultic Groups \& Religious Culture, Beijing Union University, P.R.China \\ Correspondence: Baoxiang Fan, Center for the Study of Cultic Groups \& Religious Culture, Beijing Union University, \\ P.R.China, 100101, P.R.China. E-mail: pow66@163.com
}

Received: February 22, 2018

Accepted: March 25, 2018

Online Published: March 28, 2018

doi:10.11114/smc.v6i1.3143

URL: https://doi.org/10.11114/smc.v6i1.3143

\begin{abstract}
The paper mainly deals with the question on strategies of network communication applied by destructive cult groups and new tendencies in the mobile era. These cults usually take advantage of the Internet environment to set up and develop online positions, working jointly with offline activities. The author conducts a case study, which is based on the method of content analysis, towards Xin Tang Ren website operated by Falun Gong group to demonstrate its unique communication characteristics. The case study reveals the usual online publicity strategies of Falun Gong and new tendencies applied in the mobile era. In the Internet time, the more open and cross-border thinking should be expected to strenuously create a novel anti-cult path with Chinese characteristics.
\end{abstract}

Keywords: information communication, survey research, content analysis, destructive cults

\section{Introduction}

In the past decades, many countries, including China, have been constructing information network infrastructure and developing various online applications. The Internet enormously facilitates people's daily communication. It supports many intelligent scenarios such as online shopping and job recruitment. And at the same time, destructive cults normally take advantage of the virtual world to pool in newcomers to scale up their organizations. It can be acknowledged that each individual, usually taken as a kind of precious resource, is one of the critical factors in the process of achieving the goals set by any given teams or organizations. The number of members could be an important indicator to show the influence power of any groups.

\subsection{The Fundamental Theory of Destructive Cults}

The word "cult" comes from the root word of "culture". It technically means a system of worship, esp. one that is different from the usual and established forms of religion in a particular society in Longman dictionary of contemporary English. A destructive cult is a fraudulent establishment in the name of religion, qigong or others. Deifying its leader and disguised under cloak of science and religion (Zhengfeng Liu, 2012). It forms on the surface a strong and effective stimulus for the realization of individual expectations. Robert Jay Lifton, who is a famous neuroscientist, presented some remarkable characteristics of destructive cults in his book named "Cult Formation", the top one of which is that any cults of this kind has a paramount leader worshipped undoubtedly by other members(Rick Alan Ross, 2015). Destructive cults often advocate fallacies like "saving mankind and saving the ordinary", and seduce them to become dedicated to the leader to achieve their self-fulfillment. These followers gradually lose their rational judgment, drift away from correct emotional values and finally will be mentally controlled at an appropriate time.

\subsection{One Classic Example of Destructive Cults}

Falun Gong is one of the classic examples of destructive cults. The paramount of Falun Gong has unlimited power. The authoritarian control and the extreme demand for adherence to group rules or beliefs are the major features. The idea of "truth, goodness and tolerance" preached by "Falun Gong" is actually the shackles on its believers (Rick Alan Ross, 2015). In Samuel Luo's book named "What Falun Gong really teaches", he said that one of the most important and common methods that Falun Gong uses to control their followers can be called "exclusion of the outside world." He

\footnotetext{
*This paper is phased research results of Beijing social science fund research base project (project number: 14JDZHB008), Beijing municipal education commission on social science plan project (project number: SM201511417001) and Beijing municipal government on research project named "research on online publicities".
} 
worried the most that ever since his parents became Falun Gong practitioners they have abandoned seeking medical treatment when needed (Samal Luo, 2005). This group has realistic and potential harm to the society and individuals. And throughout its various network channels, such as Ming Hui Net, Da Ji Yuan, Xin Tang Ren, it vigorously promoted the "need to conform to the changes of astronomical phenomena better" and many people got lost and found hard to return back to normal life.

\section{Materials and Methods}

The main objective of this paper is to probe the strategies and logics of network communication applied by destructive cults and new tendencies in the mobile era in hope of obtaining clues on anti-cult path relating to online information communication. The chief methods used in this paper include quantitative methods and survey research.

\subsection{Quantitative Methods}

Generally, the two main approaches to research are deductive and inductive, and there are two broad techniques to approach research: quantitative methods and qualitative methods of research (Saunders, M. Lewis, P. \& Thornhill, 2000). Quantitative research aims to be objective and collects and uses numerical data. With this type of research the results are given numerical values and the researcher uses a mathematical and statistical treatment to help evaluate the results. The content analysis used in the paper belongs to quantitative methods. It aims at studying documents and communication artifacts, which can be texts of various formats, pictures, audio or video. Social scholars use content analysis to quantify patterns in communication, in a replicable and systematic manner (Alan, Bryman, 2011). The content analysis paves the way to collect the primary data.

\subsection{Survey Research}

Survey research is one of the most important areas of measurement in applied social research. A single survey is made of at least a sample, a method of data collection and individual questions or items that become data that can be analyzed statistically. A single survey may focus on different types of topics such as preferences, opinions, behavior, or factual information, depending on its purpose (George Beam, 2012). The authors collected the primary data specifically from the sample reports of one comprehensive website operated by Falun Gong. The reports were chosen randomly from nearly all columns on the website for the sake of avoiding bias. Some facets of each report, such as the most repetitive words and media forms, are screened and then classified. Then the results can be analyzed statistically and the corresponding conclusions drawn. In addition, some desk research was carried out in the paper, including information gathered from books, journals, etc.

\section{The Closer Link Between Destructive Cults and the Internet}

The people who are members of destructive cults belong to special minority groups in whole society. They have transformed themselves into the kind of ideology with cranky or narrow-minded state, who usually just admit things they believe in and don't bear any dissenters. Their practical needs, such as seeking for free of misfortune situations or possessing healthier bodies, probably are contributors making them struck into misfortune caused by destructive cults. Yet expanding of these cults mainly depends on interpersonal dissemination in the past. The harmful thoughts are passed on by mouth to mouth in the circle of acquaintances, like relatives, friends and neighbors. These groups' members are isolated in varying degree, away from mainstream of society and are much less likely to flow to other socio-groups.

According to a set of data released in "The 41th China Internet Development Statistics Report in 2017": up to December, the population of Chinese cyber citizens reached 772 million, the popularizing rate of Internet climbed to $55.8 \%$. In addition, the number of people logging on the net via cell phones rocketed to 753 million, and the proportion of them to all cyber citizens in population took up 97.5\%. Such a large size of population of Internet users is just after the total quantity of the whole population in China and India. Therefore, network communication has been the way of life and it becomes the normal means for real-time exchanging conveniently. With the rapid development of information technology, it is much easier and quicker to communicate with each other, especially in the current mobile Internet era. More ways of information communication, which have been accepting by individuals and groups, are extensively used in daily life.

Under such circumstances, destructive cultic groups like Falun Gong which is mentioned above, take the Internet as a crucial platform to enhance communication effects and expand their influence. The Internet makes it easy for all of us to communicate with someone from any number of regions or countries. It also allows us to gather information in a real-time fashion from news sources around the world. It especially provides a large source of novel and appealing stimuli, particularly with respect to unknown materials or unverified information. Novelty-seeking and cue-conditioning are fundamental processes underlying preference and approach behaviors implicated in disorders of addiction (Paula Banca, 2016). Destructive cults take advantage of the virtual world to set up and develop online spaces, working jointly 
with offline activities. The websites, forums and online media dealing with social interactions are the potential tools to publicize their extreme thoughts. Taking Falun Gong as an example, its typical websites can be divided into two categories. One is comprehensive websites involving a wide variety of topics. Another is special ones only associated with relevant information of Falun Gong. They utilize online channels to attract new believers by claiming they can "purify the soul" and have an extraordinary function of self-transcendence. When a promise from some interest group meets our expectations, viewers are more likely to be tempted to join these groups. Therefore, the Internet, to some extent, makes its users to have more opportunities to be exposed to the extreme thoughts and paves the way for continuous growth of destructive cultic groups.

\section{Online Dynamics of Destructive Cults}

With the rapid development of information technology and the popularity of network communication around the world, the Internet has been the growing driving force in information communication by some destructive cults. The author collected and observed the online spaces of Falun Gong, from which certain regular patterns could be found.

\subsection{Setting up Comprehensive Websites to Advocate Thoughts of Destructive Cults}

It is a real fact that setting up comprehensive websites provides a suitable growth environment for destructive cults, mainly because it could make its normal viewers to be more accessible to cultic theories and affect them negatively and secretly. As a whole, there are many typical sites of this kind overseas to publicize Falun Gong, such as World Door, Kan Zhong Guo, Xin Tang Ren, etc. The basic characteristic of these sites above is a wide variety of topics, which impels their publicity hidden to some degree. Their extreme thoughts can be likened to embedded advertisements in films and television works. The operators of these websites are trying to obtain expected communication effects by embedding their speeches directly or indirectly among diversified contents with the real aim at making viewers believe. Their potential target audiences are the ones who have tendencies of being transformed into members of destructive cults. In this way could the Falun Gong group scale up to keep or even enhance its influences.

The author conducted a case study with the method of content analysis on Xin Tang Ren website operated by Falun Gong group. We randomly chose 200 reports, spanning from April to May 2016, published in the "top-rated news" area on the homepage and examined each of them in representative dimensions, including the themes, keywords, media formats and involving extreme thoughts or not. Throughout gathering the information above, there has been found the regular publicity strategies from the chosen reports. They can be categorized into four basic types: the normal reports, negative ones with tendency of anti-government speeches, the ones for publicizing the speeches of destructive cults indirectly and the ones directly (A-D stand for the 4 types respectively below).

Table Statistics table of reports edited in different publicity strategies

\begin{tabular}{l|c|c|c|c}
\hline $\begin{array}{c}\text { Publicity } \\
\text { Strategies themes }\end{array}$ & A & B & C & D \\
\hline International Affairs & 31 & 0 & 3 & 0 \\
\hline Domestic Politics & 10 & 1 & 32 & 5 \\
\hline Science and Education & 14 & 0 & 0 & 0 \\
\hline Commercial News & 6 & 0 & 1 & 0 \\
\hline Hot Spot Issues & 3 & 2 & 7 & 0 \\
\hline Citizen Reports & 26 & 2 & 6 & 0 \\
\hline Sports News & 4 & 0 & 0 & 0 \\
\hline Criminal Cases & 6 & 1 & 0 & 0 \\
\hline Health Care & 8 & 0 & 0 & 0 \\
\hline Entertainments & 28 & 1 & 3 & 0 \\
\hline TOTAL & 136 & 7 & 52 & 5 \\
\hline
\end{tabular}

The table above clearly reveals that the process of publicity of Falun Gong is rather hidden on the website. They take advantage of the virtual environment to craftily publicize their extreme thoughts, which are deliberately hidden in materials of the neutral public topics all reported normally, such as Science and Education, Sports News, Health Care, with the total number of 136 pieces. However, type $\mathrm{D}$, materials of which are all related to domestic politics, takes up mere $2.5 \%$ of the whole. Moreover, the percentage of the number of reports on domestic politics in $\mathrm{C}$ group reaches $61.54 \%$. Thus, we could sense a usual way of information embedding technique, namely putting the harmful speeches into the reports on politics. All contents on the website look more real and objective by the special layout tactic at the cost of reducing the proportion of their intended speeches to be publicized by Falun Gong members. It is through this way that the target audiences can be more likely to be enchanted and recruited.

Throughout thorough observation of each of the sample reports, especially the reports with C and D publicity strategies, the online communication has some remarkable features as follows. 
(1)Utilizing the agenda-setting theory flexibly. Agenda-setting theory describes the "ability to influence the importance placed on the topics of the public agenda" (McCombs M, Reynolds A, 2002). If a news item is covered frequently and prominently, the audience will regard the issue as more important (Glenn G.Sparks, 2008). The sample reports have shown frequent application of agenda-setting theory. Almost all 57 reports with $\mathrm{C}$ and D publicity strategies can be found such wordings as so-called "super-world" value against society. The words, like self-transcendence, immortal, are repeated among these reports in varying degree. Moreover, there appeared a rather weird sample report. The news lead is only a topic to be discussed by its viewers and its main body is a large region filled with plenty of discussion posters. However, two appealing reports ahead with similar topics and guidance comments pave the way for the discussion direction if observing the news area as a whole. Most netizens, who play the role of conspiracy with Falun Gong, literally give their opinions unconsciously based on the preceding directive reports. So it can be learnt that the people operating Xin Tang Ren website applied the agenda-setting theory not just in editing almost every separate report, but designing webpage layouts. If someone frequently read the websites of this kind, he or she may be driven to have unconscious preference and approach decisions in daily life.

(2) Selecting hot button issues of society. The source materials of the most sample reports are based on current affairs, and one of the apparent features is a very wide variety of keywords and its extremely low repetition rate. However, it seems that there exists vague order among diversified materials. Of all reports in B to D groups, the keywords in relatively high frequency are associated with "Protesting and decryption" (9 and 6 times respectively in the whole sample), from which the taste of this website could be explicitly sensed. It is probably the normal strategy that select and tailor the fascinating news materials catering to audiences' tastes with the purpose of embedding Falun Gong's teachings effectively. The real intention of Xin Tang Ren website is likely to make full use of these reports to publicize indirectly the extreme thought in its expecting direction.

(3)Spreading online rumors. Rumors are also often discussed with regard to "misinformation" and "disinformation". The former is often seen as simply false and the latter seen as deliberately false (Gordon W. Allport, 2003). The rumors on the websites operated by Falun Gong group belong to the latter. Many sample reports, which are quite deceptive, are normally grounded on facts, but compiled distortedly or exaggeratedly. These rumor reports have a progressive structure, namely listing news firstly and then groundless comments. For instance, one report said that the stormy weather occurred in west region of China yesterday makes it difficult for pupils to go to school. Most of the mountain roads from their homes to school are muddy and uneven. It then remarked the pupils will have no future in such a tough environment and imply the uncertainty over the nation's future. Another type of rumor reports is outright fictional, mainly because there are no relevant events reported from the mainstream media of the same period. Five reports in D group are of this league. One ridiculous sample report said that the MH370, a missing plane run by Malaysia Airlines had been concealed by Falun Gong practitioners, who claiming that they can detect the highest principles of the universe. Then the following part was the long Falun Gong's teachings. One apparent feature of these five reports is its unusually long comments aimed at guiding the viewers, who generally lack relating references, to accept certain fallacies which have no basis in fact.

\subsection{Exploiting the Mobile Internet to Accelerate Communication of Thoughts Stemming From Destructive Cults}

With the growing popularity of mobile Internet and socializing applications, the ways by which a large majority of people read daily information habitually have been through the various mobile terminals, such as cell phones and panel computers. The popularity of surfing Internet with cell phones makes average netizens to get much more opportunities to be exposed of destructive cults' speeches. It could remarkably be reflected that there exists tremendous potential in mobile network from the super-high number of people logging Internet with cell phones. Under such a circumstance, destructive cults' teachings can be enhanced and more influenced by means of mobile network, whose noticeable advantage is its enormous power of information communication.

It can be easily found that one of its apparent features is to cater for netizens' practices in the mobile era. Some websites, like A Bo Luo, Xi Wang Zhi Sheng, share similar traits as follows. Firstly, putting more pictures intentionally is a noticeable feature. The speeches of Falun Gong are normally along with series of pictures or large high definition images, which create strong visual impact for viewers. Secondly, adding the ratio of videos to words is another tactic. The short videos concerning various themes, certainly including the teachings of Falun Gong, flood these websites overseas. Thirdly, introducing hyperlinks of social networking tools is another feature on these websites. It enables viewers to get possibilities to connect destructive cults' members online. This way of social interaction is an upgraded one compared with information communication in person. At present, WeChat, which is the most welcomed in China, Facebook, Twitter, are representatives of social networking tools that are popular in communicating in acquaintance circles. The traits mentioned above not only promote the feeling of reality, but also cater for cyber citizens' practices, which include reading fragmentation and novelty hunting, in the mobile times. 
Taking the media formats as an example, from the 200 sample reports observed in the case study above, in D group alone, the proportion of reports in video format is $40 \%$. By contract, the video reports just take up $16.2 \%$ in group A. In group C, $42.9 \%$ of the reports are along with series of images. But of the reports in group A, the proportion is merely $25.7 \%$. Thus, media formats suitable for communication in mobile era apparently have been applied more in reports relating to Falun Gong's teachings.

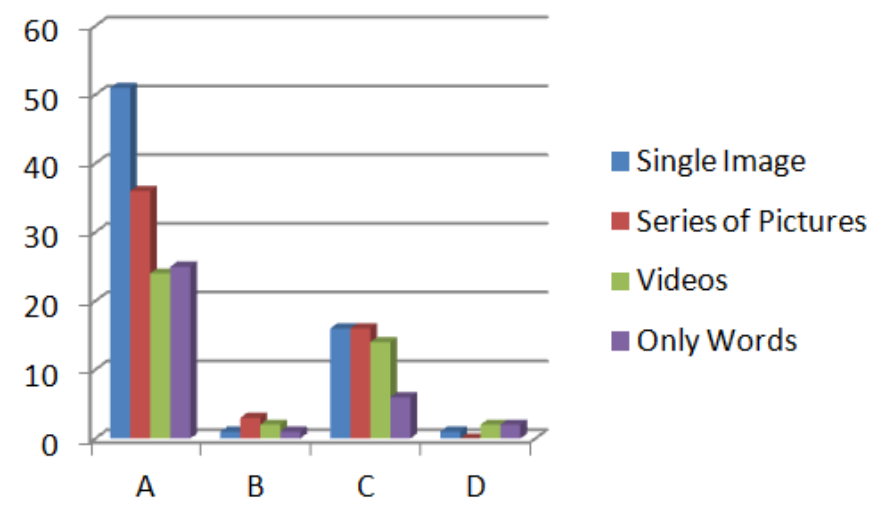

Chart 1. Statistics of frequencies of different media formats used in sample reports

Another feature is that the interpersonal communication has been stretched with the aid of mobile social networks. The mobile information transmission shares the similar mode with the offline acquaintance communities, namely the net-shaped transmission with multiple nodes. It can also be called as scale-free network technically (Albert R, Barabasi A. L, 2002). In the chart below, the square-shaped black dot near the middle stands for the information origin, such as a piece of news on a website. The surrounding nodes with various colors represent the cults' members directed in the process of communication. Yet the black nodes among them indicate that part of believers play an important role in secondary transmission, which can spread the information quickly inside the online communities they belong to. The number of people receiving the information from each black node is apparently limited, but the power of transmission when accumulating these nodes will be huge (Watts D J, Strogatz S H, 1998). It is going to be far beyond the traditional interpersonal communication.

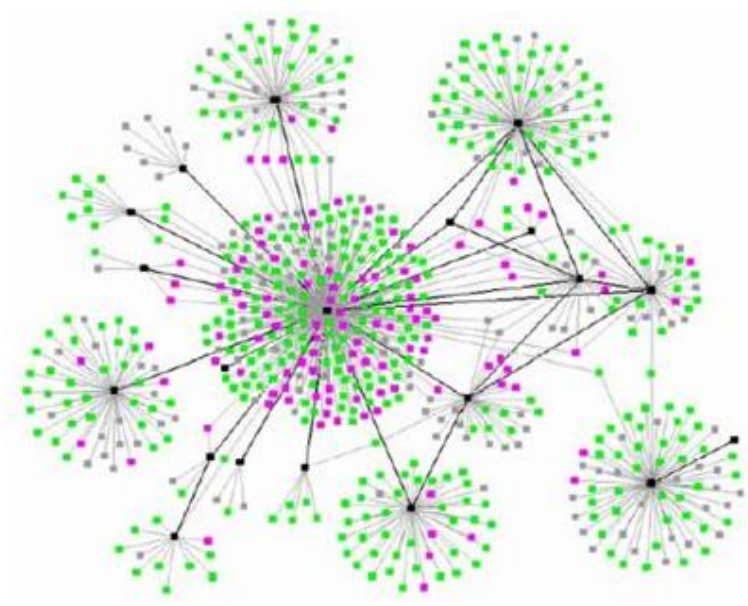

Chart 2. Communication mode with multiple nodes

In a survey research, we had an in-depth interview with a former Falun Gong member, who was an undergraduate male student in Beijing. He had been surrounded by his family members who strongly believe in Falun Gong and joined in a WeChat group filled with Falun Gong practitioners. Then, the student was recruited in the end. He recalled he often see the statements from online acquaintance circles that practice can help him achieve "perfection". Fortunately, he was moved out by a neighboring community in the end.

The tools like websites in mobile versions, community forums, we-media spaces and mobile applications, have been being exploited as test ones for destructive cults' communication. For example, the major websites created by Falun Gong group successively release their sites in mobile versions or APP compatible with diversified mobile terminals. A mobile application compatible with various mobile terminals, such as Android, iPhone, iPad, has been emerged on the 
website of Xin Tang Ren TV Station. The slogan in large size, which is written "Xin Tang Ren Mobile Platform is the reliance for grasping world affairs in time", is rather noticeable to appeal viewers to install it. Moreover, any given site provides their viewers with discussion areas specifically for each piece of news in nearly all columns. In addition, there are sharing channels in prominent positions which are aimed at spreading information towards the well-known social media. Therefore, it is a clear tendency to exploit advantages of different tools with an aim at expanding scope and increasing effect of destructive cults' communication online.

\section{Conclusions}

From the research, some clues can be obtained on the ways of controlling or governing destructive cults. The conclusions of this paper are two parts as follows. Firstly, the case study reveals the frequently used strategies on online communication, such typical ones as using the agenda-setting theory flexibly, selecting hot issues of society and spreading online rumors. The cult's members serving this website are trying to obtain the expected communication effects by embedding their speeches directly or indirectly among diversified contents with the real aim at making more viewers to believe in. Secondly, it has been found new tendencies applied in the mobile era, such as catering for netizens' practices and building communication forms in pluralism. The Specific features, like putting more pictures intentionally, adding ratio of videos to words, using various mobile applications.

In the fast changing Internet era, the anti-cult works should be concentrated in comprehensive governance and prevention, especially strengthening online anti-cult capabilities intensively and extensively. The various technological applications online themselves actually contain new potential paths of anti-cult works. For example, with deeper applications of cloud computing and mobile media, it will be more possible to integrate and analyze data information on websites of cultic groups like Falun Gong, from which we could be lifting our communication effects to do anti-cult work more effectively. It also can't be ignored that real-time interactive communication online between cultic members and ordinary netizens will probably a new trend on cults' communication in the near future. Above all, in the Internet time, the more open and cross-border thinking should be expected to strenuously create a novel anti-cult path with Chinese characteristics.

\section{References}

Alan, B. (2011). Business research methods. Bell, Emma, 1968- (3rd edition.) [M]. Cambridge: Oxford University Press, 2011

Albert, R., \& Barabasi, A. L. (2002). Statistical mechanics of complex networks [J]. Rev. Mod. Phys., 2002. https://doi.org/10.1103/RevModPhys.74.47

George, B. (2012). The Problem with Survey Research [M]. New Brunswick, NJ: Transaction, 2012

Glenn, G. (2008). Sparks: Media Effects Research: A Basic Overview $2^{\text {nd }}$ Edition [M].Beijing: Peking University Press. 2008

Gordon, W. (2003). All port: Rumor Psychology [M]. Shenyang: Liaoning Publishing House. 2003

Liu, Z. F. (2012). Legal Governance of Evil Cults [M].Beijing: Social Science Academic Press, 2012

McCombs, M., \& Reynolds, A. (2002). "News influence on our pictures of the world". Media effects: Advances in theory and research, 2002

Paula, B. (2016). Novelty, conditioning and attention bias to sexual rewards [J]. Journal of Psychiatric Research, 2016

Rick, A. R. (2015). Cults inside out: How people get in and can get out [M]. Hong Kong: Chinese peace books Ltd., 2015

Samal, L. (2005). What Falun Gong really teachers. http://www.icsahome.com/articles/what-falun-gong-really-teaches, International Cultic Studies Association, 2005

Saunders, M., Lewis, P., \& Thornhill, A. (2000). Research Methods for Business Students, $2^{\text {nd }}$ Edition [M]. Prentice Hall, 2000

Watts, D. J., \& Strogatz, S. H. (1998). Collective dynamics of 'small world' networks [J]. Nature, 1998. https://doi.org/10.1038/30918

\section{Copyrights}

Copyright for this article is retained by the author(s), with first publication rights granted to the journal.

This is an open-access article distributed under the terms and conditions of the Creative Commons Attribution license which permits unrestricted use, distribution, and reproduction in any medium, provided the original work is properly cited. 